\title{
Ciecze stosowane do obróbki plastycznej blach stalowych na zimno
}

\begin{abstract}
W artykule przedstawiono środki smarowe stosowane do obróbki plastycznej blach stalowych na zimno. Szczególny nacisk położono na emulsje wodne używane w tym procesie. W części doświadczalnej omówiono wstępne badania nad wytworzeniem oleju emulgującego przeznaczonego do obróbki plastycznej blach stalowych na zimno.
\end{abstract}

Słowa kluczowe: środki smarowe do walcowania, emulsje do walcowania.

\section{Liquids used for cold forming of steel sheets}

The article discusses lubricants used in cold forming of steel sheets, with special emphasis on water emulsions used in the process. In the experimental part, initial tests were carried out on the production of emulsifying oil used during cold forming of steel sheets.

Key words: rolling lubricants, rolling emulsions.

\section{Wprowadzenie}

Ciąg operacji związany z procesem walcowania obejmuje wiele działań, które wpływają na ostateczną jakość gotowego wyrobu. Pierwszą operację stanowi walcowanie na gorąco, w czasie którego uzyskuje się taśmy blachy grubej, zwijanej następnie w kręgi. Kręgi przed walcowaniem na zimno poddawane są odpowiedniej obróbce, mającej na celu oczyszczenie powierzchni blachy [17].

Walcowanie na zimno nie zawsze następuje bezpośrednio po przedstawionych powyżej przygotowaniach, niekiedy ma to miejsce po upływie dłuższego czasu. $Z$ tego powodu oczyszczona taśma jest zabezpieczana przed korozją poprzez zanurzenie w oleju konserwującym, który następnie zostaje zużytkowany w pierwszych przepustach, jako olej do walcowania na zimno. Po walcowaniu taśmę poddaje się odtłuszczeniu w sposób elektrolityczny - w przypadku blach przeznaczonych do ocynkowania, lub przez wyżarzanie w at- mosferze gazu obojętnego, gdy proces jej wykończenia jest inny niż ocynkowanie $[8,13]$.

Sposób chłodzenia i smarowania taśmy i walców zależy od systemu układu chłodząco-smarującego walcarki [5]:

- w systemie podwójnym taśma i walce zraszane są olejem lub emulsją olejowo-wodną, a ponadto walce chłodzone są wodą, - w systemie pojedynczym taśma i walce chłodzone są emulsją, która spełnia równocześnie rolę środka smarującego i chłodzącego.

W czasie walcowania, na skutek nacisku walców na obrabiany materiał, następuje zmiana kształtu oraz zmiana struktury obrabianego materiału - wpływająca na polepszenie jego właściwości mechanicznych. Między powierzchnią walca a walcowaną blachą występuje tarcie, którego wielkość jest zależna od jakości powierzchni blachy, jakości powierzchni walców, szybkości walcowania i rodzaju materiału smarowego $[3,11]$.

\section{Środki smarowe stosowane w procesie walcowania}

Środki smarowe stosowane w procesie walcowania stali na zimno można podzielić na trzy grupy: oleje, emulsje typu olej w wodzie $(\mathrm{O} / \mathrm{W})$ i roztwory wodne. Najczęściej w procesie walcowania wykorzystuje się oleje i emulsje wodne, 
przy czym emulsje używane są przy większych prędkościach walcowania. W zależności od rodzaju walcowanej blachy i warunków procesu walcowania na zimno używane są oleje thuszczowe pochodzenia roślinnego i zwierzęcego, oleje mineralne, naturalne i syntetyczne oleje estrowe [8].

Oleje tłuszczowe wykazują niską stabilność termiczną, jednocześnie charakteryzując się dobrymi właściwościami smarnymi. Poprawę stabilności termicznej można zaobserwować w przypadku modyfikowanych tłuszczów naturalnych, a także naturalnych i syntetycznych estrów kwasów tłuszczowych. Gorsze właściwości smarne, w odniesieniu do olejów tłuszczowych, wykazują oleje mineralne $[1,16]$.

W celu osiągnięcia najwyższych możliwych prędkości walcowania, przy jednoczesnym zachowaniu bardzo dobrej jakości walcowanych blach, zamiast olejów stosowane są emulsje typu O/W. Emulsje O/W w porównaniu z olejami charakteryzują się lepszymi właściwościami chłodzącymi, zmniejszają zagrożenie przeciwpożarowe oraz mają wpływ na poprawę warunków pracy poprzez ograniczenie mgły olejowej. Jednocześnie wymagają szczególnej kontroli stabilnej zawartości oleju w wodzie, stałej wartości pH i braku zawartości zanieczyszczeń [9].

Roztwory wodne są najnowocześniejszymi rozwiązaniami stosowanymi w procesie walcowania stali na zimno. Ujawniona w patencie [19] wodna kompozycja smarowa składa się ze środka powierzchniowo czynnego i fosforanu alkilowego, które rozpuszczone w wodzie tworzą film smarujący na powierzchni metalu oraz zapewniają doskonałą ochronę przeciwkorozyjną. Innym rozwiązaniem [20] jest kompozycja rozpuszczonych w wodzie polimerów liniowych lub rozgałęzionych, zawierających jedną lub więcej grup hydrofilowych.

W skład olejów do walcowania stali na zimno wchodzą również dodatki funkcyjne, tj.:

- emulgatory,

- dodatki przeciwzatarciowe (EP),

- dodatki przeciwzużyciowe (AW),

- dodatki przeciwkorozyjne,

- dodatki przeciwpienne.

Oleje emulgujące, stosowane w procesach walcowania, jako podstawowy składnik zawierają w większości przypadków mineralne oleje bazowe. Najczęściej używanymi środkami smarnymi w walcowaniu są emulsje wodno-olejowe typu $\mathrm{O} / \mathrm{W}$. W procesie walcowania spełniają one wiele funkcji, przy czym do najważniejszych należą $[13,15]$ :

- zabezpieczenie smarowania w kotlinie walcowniczej w celu zmniejszenia oporów tarcia w układzie walce-blacha,

- odprowadzenie ciepła wytworzonego w procesie walcowania.

W trakcie walcowania w kotlinie walcowniczej, na skutek wzrastającego ciśnienia między walcem a walcowaną blachą, następuje przemiana fazowa w emulsji: z typu O/W na $\mathrm{W} / \mathrm{O}$. W zależności od rodzaju walcowanego materiału, warunków walcowania i założonych wymagań dla odwalcowanej taśmy dobierany jest odpowiedni środek smarowy do procesu walcowania. Emulsjom stosowanym w procesach walcowania blach na zimno stawia się wymagania, z których najistotniejsze to $[4,14]$ :

- łatwość sporządzenia produktu gotowego do użycia (najczęściej z koncentratu),

- zachowanie stabilności w temperaturze od 25 do około $75^{\circ} \mathrm{C}$,

- przystosowanie emulsji do pracy w systemie cyrkulacyjnym (biostabilność),

- dostateczna smarność, lecz nie tak duża, aby powodować trudności podczas wciągania końców zwojów przez walce,

- dobre właściwości zwilżające,

- konieczność działania jako smar dla łożysk w walcarkach,

- zapewnienie ochrony przeciwkorozyjnej blachy w okresie międzyoperacyjnego składowania,

- zachowanie stabilności podczas procesów odfiltrowywania zanieczyszczeń.

Wybór środka smarowego zależy od rodzaju walcowanej blachy i warunków walcowania. Szczególnie dobre właściwości smarne w warunkach walcowania wykazują thuszcze. Jednak z uwagi na niezbyt wysoką stabilność termiczną mogą one być stosowane jako środki smarowe w przelotowym systemie smarowania lub jako fizycznie działające dodatki smarne do olejów w cyrkulacyjnym systemie smarowania $[12,15]$.

Nieco gorsze właściwości smarne wykazują oleje mineralne. Jednak z uwagi na wysoką stabilność termiczną są one najpowszechniej stosowanym środkiem smarowym w procesie walcowania stali na zimno. Oleje te mogą być używane w cyrkulacyjnym systemie smarowania. Jednym z pierwszych tłuszczów zastosowanych do wytwarzania olejów walcowniczych był olej palmowy. Przez wiele lat uznawano, z uwagi na właściwości smarne, że jest on niezastąpiony, mimo obserwowanej zmienności jego właściwości w zależności od warunków klimatycznych $[2,8]$.

W tablicy 1 przedstawiono współczynniki tarcia dla różnych substancji smarujących uzyskane w walcarce modelowej [6].

Oleje mineralne powinny mieć umiarkowanie dużą lepkość oraz wąski zakres temperatur wrzenia. Właściwości te są istotne $\mathrm{z}$ uwagi na proces usuwania oleju z powierzchni blachy w trakcie wyżarzania rekrystalizującego. Zalety te oraz niski koszt olejów naftowych powodują, że mimo ich gorszych właściwości smarnych, w porównaniu z tłuszcza$\mathrm{mi}$, są one powszechnie stosowane w przeróbce plastycznej metali [10].

Coraz wyższe wymagania stawiane wobec walcowanej blachy powodują konieczność wprowadzenia w skład oleju wal- 
Tablica 1. Współczynniki tarcia dla różnych środków smarowych [6]

\begin{tabular}{|l|l|}
\hline \multicolumn{1}{|c|}{ Srodek smarowy } & $\begin{array}{c}\text { Współczynnik } \\
\text { tarcia }\end{array}$ \\
\hline Walcowanie na sucho & 0,113 \\
\hline Olej palmowy & 0,019 \\
\hline Olej rycynowy & 0,019 \\
\hline Tłuszcz wieprzowy & 0,015 \\
\hline Thuszcz wielorybi & 0,023 \\
\hline Olej maszynowy & 0,045 \\
\hline Olej wrzecionowy & 0,046 \\
\hline Olej emulgujący na bazie oleju naftowego & 0,052 \\
\hline
\end{tabular}

cowniczego dodatków podwyższających właściwości smarne. Najbardziej popularne są dodatki EP (Extreme Pressure). Najczęściej stosowane są organiczne związki siarki i fosforu, dodatki siarkowe w postaci siarczków i wielosiarczków w ilości $0,4 \div 1,2 \%(\mathrm{~m} / \mathrm{m})$ w przeliczeniu na siarkę wprowa- dzoną do oleju. W procesie walcowania w warunkach tarcia granicznego w kotlinie walcowniczej związki siarki reagują z metalem, zapobiegając uszkodzeniom powierzchni poprzez eliminację powstawania mikrozgrzewań i związanym z tym wyrywaniem cząstek metalicznych. Drugą grupą dodatków EP - wprowadzanych do składu olejów walcowniczych - są dodatki fosforowe. Efektywne działanie związków siarkowych i fosforowych wynika z tego, że wchodzą one $\mathrm{w}$ reakcję $\mathrm{z}$ metalem poddawanym deformacji plastycznej, którego powierzchnia pokrywa się warstewką wytworzonego związku. Na skutek tego zmieniają się właściwości fizykochemiczne obrabianego materiału i w ten sposób dodatki EP wpływają na zmianę warunków tarcia. Przy czym inny jest charakter warstewki powierzchniowej tworzonej w reakcji stali z dodatkami siarkowymi, inny z fosforowymi. W przypadku związków siarki wytworzony siarczek metalu (przyjmuje się, że jest to siarczek żelaza Fe) jest kruchy i łatwo ścieralny, natomiast fosforan metalu przylega adhezyjnie do powierzchni metalu $[9,18]$.

\section{Przeprowadzenie wstępnych badań laboratoryjnych nad wytworzeniem cieczy obróbczej}

Jako olej bazowy zastosowano olej podstawowy SAE 30/95. Produkowany jest on w Grupie LOTOS S.A. w trakcie zachowawczej przeróbki ropy naftowej. Wytwarza się go $\mathrm{z}$ destylatów próżniowych, selektywnie rafinowanych furfurolem, odparafinowanych metodą rozpuszczalnikową, a następnie poddanych rafinacji wodorem. Typowe właściwości oleju SAE 30/95 przedstawiono w tablicy 2.

W pierwszym etapie prac laboratoryjnych przeprowadzono badania nad doborem emulgatorów pozwalających na otrzy- manie stabilnych emulsji olejowo-wodnych. Spośród dostępnych na rynku emulgatorów wytypowano sześć: 1 - na bazie alkoksylowanego kwasu thuszczowego, 2 - na bazie alkoksylowanych alkoholi, 3 - na bazie alkoksylowanych nonylofenoli. Przeprowadzono wstępne badania kompatybilności oleju bazowego z emulgatorami. W tym celu zestawiono próbki, w skład których wchodził olej bazowy oraz emulgator. Wszystkie próbki zestawiano z takim samym udziałem oleju bazowego i badanego emulgatora, $w$ takich samych warunkach, $\mathrm{tj}$.:

Tablica 2. Właściwości oleju SAE 30/95

\begin{tabular}{|c|c|c|c|}
\hline Właściwości & Jednostka & Wartości & Metoda badań \\
\hline Wygląd w temperaturze $20^{\circ} \mathrm{C}$ & - & przezroczysty, bez zawiesin & wizualnie \\
\hline Lepkość kinematyczna w temp. $100^{\circ} \mathrm{C}$ nie niższa niż & $\mathrm{mm}^{2} / \mathrm{s}$ & 10,3 & PN-EN ISO 3104 \\
\hline Lepkość kinematyczna w temp. $40^{\circ} \mathrm{C}$ & $\mathrm{mm}^{2} / \mathrm{s}$ & 89,0 & PN-EN ISO 3104 \\
\hline Wskaźnik lepkości & - & 95 & PN ISO 2909 \\
\hline Temperatura płynięcia & ${ }^{\circ} \mathrm{C}$ & -9 & PN ISO 3016 \\
\hline Temperatura zapłonu & ${ }^{\circ} \mathrm{C}$ & 270 & PN-EN ISO 2592 \\
\hline Pozostałość po koksowaniu & $\%(m / m)$ & 0,01 & PN-EN ISO 10370 \\
\hline Liczba kwasowa & $\mathrm{mg} \mathrm{KOH} / \mathrm{g}$ & 0,015 & PN-88/C-04049 \\
\hline Pozostałość po spopieleniu & $\%(m / m)$ & nie zawiera & PN-EN ISO 6245 \\
\hline $\begin{array}{l}\text { Działanie korodujące w temp. } 100^{\circ} \mathrm{C} \text { w ciągu } 3 \text { godzin } \\
\text { na płytkach z miedzi }\end{array}$ & stopień korozji & 1 & PN-EN ISO 2160 \\
\hline Zawartość części lotnych metodą Noack’a & $\%(m / m)$ & 2,1 & PN-C-04124:2000 \\
\hline Barwa & numer wzorca & 1 & $\begin{array}{l}\text { PN ISO } 2049 \\
\text { ASTM D } 1500\end{array}$ \\
\hline Gęstość w temp. $15^{\circ} \mathrm{C}$ & $\mathrm{g} / \mathrm{cm}^{3}$ & 0,882 & PN-EN ISO 12185 \\
\hline
\end{tabular}


- w temperaturze $80^{\circ} \mathrm{C}$,

- w czasie mieszania $40 \mathrm{~min}$,

- częstość obrotów mieszadła 400 obr./min.

Tak zestawione próbki przelewano do cylindrów o pojemności $100 \mathrm{ml}$ i obserwowano, czy nie ulegają rozwarstwieniu w temperaturze pokojowej po 48 godzinach przechowywania. W przypadku, gdy próbka wykazywała jakiekolwiek oznaki niejednorodności, wykluczano z dalszych badań zastosowany emulgator. W ten sposób wytypowano kompozycje emulgatorów do kolejnych badań. Kompozycja ta składała się z jednego emulgatora na bazie alkoksylowanych nonylofenoli i dwóch emulgatorów na bazie alkoksylowanych alkoholi.

Następnie przygotowane zostały próbki zawierające kompozycję emulgatorów o sprawdzonej rozpuszczalności w oleju bazowym. Z zestawionych próbek wytworzono 5-procentowe $(\mathrm{m} / \mathrm{m})$ emulsje olejowe, przeznaczone do badań nad stabilnością. Przyjmując, że na stabilność emulsji i związaną z nią zmianę wielkości kropel oleju zdyspergowanego w wodzie mają wpływ między innymi takie czynniki jak: okresy bezruchu emulsji oraz siły ścinające, występujące w procesie intensywnego mieszania, zastosowano następujący sposób przygotowania emulsji do badania ich stabilności (tablica 3).

Emulsje wytwarzano poprzez wlewanie 15 g kompozycji olejowej zawierającej emulgatory do 285 g wody destylowanej. Powstawały one z użyciem mieszadła mechanicznego w temperaturze około $25^{\circ} \mathrm{C}$ przy $1000 \mathrm{obr}$./min w czasie 20 minut. Po zakończeniu procesu emulgowania odstawiano wytworzoną próbkę na 30 minut, w celu pozbycia się piany i małych pęcherzyków powietrza. Następnie badaną próbkę emulsji przelewano do cylindra o objętości $100 \mathrm{ml}$ i obserwowano po 24 i $48 \mathrm{~h}$.

Na podstawie powyższych wyników do dalszych badań nad wytworzeniem próbki oleju do walcowania blach stalowych na zimno użyto kompozycji emulgatorów zapewniających stabilność powstałej emulsji przy najmniejszym stężeniu emulgatorów. Takimi parametrami charakteryzował się skład emulgatorów w mieszance EM3 $(3 \%(\mathrm{~m} / \mathrm{m})$ alkoksylowany nonylofenol, $3 \%(\mathrm{~m} / \mathrm{m})$ alkoksylowany alkohol 2 i $1,5 \%(\mathrm{~m} / \mathrm{m})$ alkoksylowany alkohol 1$)$.

Tablica 3. Stabilność 5-procentowej $(\mathrm{m} / \mathrm{m})$ emulsji oleju zawierającego kompozycję emulgatorów

\begin{tabular}{|c|c|c|c|c|c|c|}
\hline \multirow{2}{*}{ Składniki mieszanki } & \multicolumn{6}{|c|}{ Skład $[\%(m / m)]$} \\
\hline & EM1 & EM2 & EM3 & EM4 & EM5 & EM6 \\
\hline Olej bazowy SAE 30/95 & 97 & 95 & 92,5 & 90 & 87 & 95 \\
\hline Alkoksylowany nonylofenol & 1 & 2 & 3 & 4 & 5 & 1 \\
\hline Alkoksylowany alkohol 1 & 1 & 1 & 1,5 & 2 & 3 & 2 \\
\hline Alkoksylowany alkohol 2 & 1 & 2 & 3 & 4 & 5 & 1 \\
\hline Wygląd próbki po 48 godzinach & jednorodna & jednorodna & jednorodna & jednorodna & jednorodna & jednorodna \\
\hline \multicolumn{7}{|c|}{ Wygląd emulsji } \\
\hline Po sporządzeniu & $\begin{array}{l}\text { jednorodna, } \\
\text { mleczna, bar- } \\
\text { wy kremowej }\end{array}$ & $\begin{array}{l}\text { jednorodna, } \\
\text { mleczna, bar- } \\
\text { wy kremowej }\end{array}$ & $\begin{array}{l}\text { jednorodna, } \\
\text { mleczna, bar- } \\
\text { wy kremowej }\end{array}$ & $\begin{array}{l}\text { jednorodna, } \\
\text { mleczna, bar- } \\
\text { wy kremowej }\end{array}$ & $\begin{array}{l}\text { jednorodna, } \\
\text { mleczna, bar- } \\
\text { wy kremowej }\end{array}$ & $\begin{array}{l}\text { jednorodna, } \\
\text { mleczna, bar- } \\
\text { wy kremowej }\end{array}$ \\
\hline Po 24 godzinach & $\begin{array}{c}\text { zagęszczona } \\
\text { emulsja na po- } \\
\text { wierzchni }\end{array}$ & bez zmian & bez zmian & bez zmian & bez zmian & $\begin{array}{c}\text { zagęszczona } \\
\text { emulsja na po- } \\
\text { wierzchni }\end{array}$ \\
\hline Po 48 godzinach & $\begin{array}{l}\text { oznaki śmie- } \\
\text { tankowania na } \\
\text { powierzchni }\end{array}$ & $\begin{array}{l}\text { zagęszczo- } \\
\text { na emulsja na } \\
\text { powierzchni }\end{array}$ & bez zmian & bez zmian & bez zmian & $\begin{array}{l}\text { oznaki śmie- } \\
\text { tankowania na } \\
\text { powierzchni }\end{array}$ \\
\hline
\end{tabular}

\section{Właściwości laboratoryjnych próbek olejów}

Na podstawie przeprowadzonych badań nad doborem surowców do wytwarzania oleju emulgującego do walcowania blach stalowych na zimno wytypowano trzy składy, w oparciu o które wytworzono próbki laboratoryjne. Próbka OW-1 zawierała emulgatory oraz inhibitor korozji i inhibitor utleniania. Kolejne dwie próbki posiadały takie same ilości emulgatorów oraz inhibitorów korozji i utleniania, dodatkowo w tych próbkach zastosowano dodatki EP. W przypadku próbki OW-2 użyto $5 \%(\mathrm{~m} / \mathrm{m})$ siarkowego dodatku EP, natomiast przy kompozycji OW-3 zastosowano 2,5\% ( $\mathrm{m} / \mathrm{m})$ dodatku fosforowego. Otrzymane próbki poddano obserwacji w zakresie jednorodności uzyskanego oleju oraz oceniono stabilność wytworzonych emulsji o stężeniu $5 \%(\mathrm{~m} / \mathrm{m})$ w wodzie destylowanej.

W tablicy 4 przedstawiono składy sporządzonych próbek oleju oraz wyniki badań stabilności uzyskanych z nich 5-procentowych $(\mathrm{m} / \mathrm{m})$ emulsji. 
Tablica 4. Składy wytworzonych próbek olejów

\begin{tabular}{|c|c|c|c|}
\hline \multirow{2}{*}{ Składniki mieszanki } & \multicolumn{3}{|c|}{ Skład $[\%(m / m)]$} \\
\hline & OW-1 & OW-2 & OW-3 \\
\hline Olej bazowy SAE 30/95 & 88,0 & 83,0 & 86,5 \\
\hline Wytypowany zestaw emulgatorów & 7,5 & 7,5 & 7,5 \\
\hline Inhibitor korozji & 4,0 & 4,0 & 4,0 \\
\hline Inhibitor utleniania & 0,5 & 0,5 & 0,5 \\
\hline Siarkowy dodatek EP & - & 5,0 & - \\
\hline Fosforowy dodatek EP & - & - & 2,5 \\
\hline Wygląd próbki po 48 godzinach & jednorodna & jednorodna & $\begin{array}{l}\text { mętna, na dnie widoczne śladowe } \\
\text { ilości rozdziału kompozycji }\end{array}$ \\
\hline \multicolumn{4}{|c|}{ Wygląd emulsji } \\
\hline Po sporządzeniu & $\begin{array}{l}\text { jednorodna, mleczna, } \\
\text { barwy kremowej }\end{array}$ & $\begin{array}{l}\text { jednorodna, mleczna, } \\
\text { barwy kremowej }\end{array}$ & $\begin{array}{l}\text { jednorodna, mleczna, } \\
\text { barwy kremowej }\end{array}$ \\
\hline Po 24 godzinach & bez zmian & bez zmian & bez zmian \\
\hline Po 48 godzinach & bez zmian & bez zmian & bez zmian \\
\hline
\end{tabular}

Dla wytworzonych próbek oleju do walcowania na zimno blach stalowych oznaczono lepkość w temperaturach 40 i $100^{\circ} \mathrm{C}$, wskaźnik lepkości i przeprowadzono badania odporności na korozję oraz właściwości smarne w aparacie czterokulowym. Wyniki badań przedstawiono w tablicy 5 .

Analizując wpływ badanych modyfikatorów tarcia na właściwości smarne oznaczone w aparacie czterokulowym, w porównaniu do wyników osiągniętych dla próbki OW-1 niezawierającej modyfikatorów tarcia, stwierdzono bardzo duży wpływ w przypadku dodatku siarkowego. Dodatek fosforowy zupełnie nie oddziaływał na oznaczane właściwości smarne. Porównanie właściwości smarnych dla badanych próbek przedstawiono na rysunku 1 .

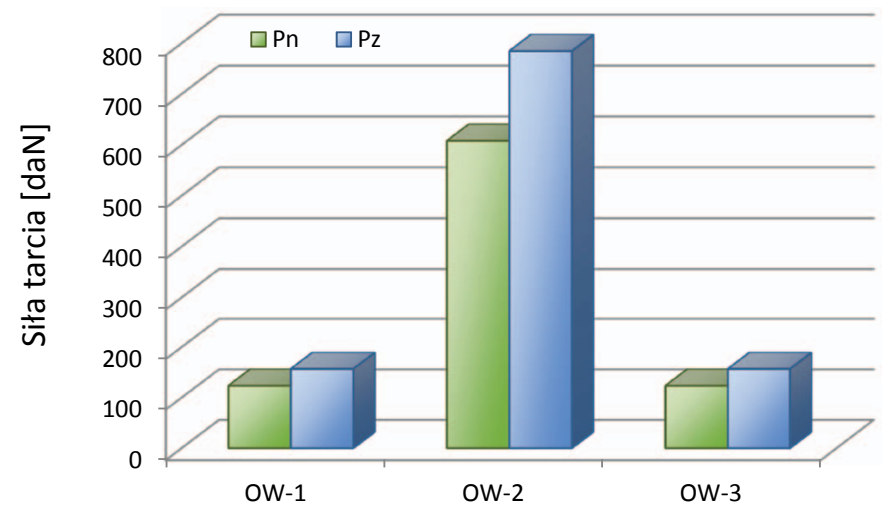

Rys. 1. Porównanie właściwości smarnych dla wytworzonych próbek oleju

\section{Badanie cząstek fazy rozproszonej metodą DLS}

Wytworzone 5-procentowe emulsje olejowo-wodne poddano badaniu cząstek fazy rozproszonej metodą DLS (Dynamic Light Scattering). Badania wykonano w aparacie Zetasizer Nano $S$, firmy Malvern Instruments, który pozwala na pomiar średnicy cząstek (zakres: od $1 \mathrm{~nm}$ do $6 \mu \mathrm{m}) \mathrm{w}$ dyspersjach cieczowych. W analizatorze jako źródło promieniowania zastosowany jest monochromatyczny, spójny laser helowo-neonowy (He-Ne), o długości fali $632,8 \mathrm{~nm}$ [7].

Z przeprowadzonej analizy DLS rozkładu cząstek fazy rozproszonej w badanych emulsjach wynika ich duża niejednorodność. Na wykresie ilustrującym wielkość cząstek fazy rozproszonej po intensywności zaobserwowano dwa piki, z których pierwszy jest dużo mniejszy. Pierwszy pik świadczy o obecności małych kropel wchodzących w skład emulsji, o średnicach od $134 \mathrm{~nm}$ do $205 \mathrm{~nm}$. Drugi większy pik reprezentuje krople o dużych średnicach: od $1191 \mathrm{~nm}$ do $1666 \mathrm{~nm}$. Krople tej wielkości stanowią od 70 do $87 \%$ badanej emulsji. W przypadku emulsji wytworzonej bez dodatków EP, a tym samych zawierającej w swoim składzie najwięcej oleju bazowego, pierwszy pik jest niewielki i stanowi około 13\% cząstek wchodzących w skład emulsji. Dla emulsji wytworzonej na bazie oleju OW-2, zawierającego w swoim składzie najwięcej dodatków, pierwszy pik reprezentujący małe krople oleju stanowił około 30\% składu uzyskanej emulsji. Na tej podstawie można stwierdzić, że mniejsze krople emulsji składały się głównie z dodatków stosowanych w próbkach olejów do blach stalowych walcowanych na zimno. Wielkość i rozkład cząstek emulsji przedstawiono w tablicy 6 . 
Tablica 6. Rozkład i wielkość cząstek w wytworzonych emulsjach

\begin{tabular}{|c|l|c|c|}
\hline \multirow{2}{*}{ Kod emulsji } & \multicolumn{2}{|c|}{$\begin{array}{c}\text { Rozkład liczebnościowy wielkości cząstek } \\
{[\%]}\end{array}$} & $\begin{array}{c}\text { Średnica hydrodynamiczna cząstki } \\
{[\mathrm{nm}]}\end{array}$ \\
\hline \multirow{2}{*}{ OW-1 } & pik pierwszy & 13,6 & 141 \\
\cline { 2 - 4 } & pik drugi & 86,4 & 1458 \\
\hline \multirow{2}{*}{ OW-2 } & pik pierwszy & 27,4 & 179 \\
\cline { 2 - 4 } & pik drugi & 72,6 & 1490 \\
\hline \multirow{2}{*}{ OW-3 } & pik pierwszy & 22,0 & 195 \\
\cline { 2 - 4 } & pik drugi & 78,0 & 1336 \\
\hline
\end{tabular}

\section{Podsumowanie}

Środki smarowe stosowane w procesie walcowania stali na zimno można podzielić na trzy grupy: oleje, emulsje typu olej w wodzie $(\mathrm{O} / \mathrm{W})$ i roztwory wodne. Oleje i emulsje należą do tradycyjnych środków, natomiast roztwory wodne są środkami nowoczesnymi, które dopiero wchodzą do zastosowania w procesach walcowania. Dobór środka smarnego do walcowania stali na zimno musi uwzględniać specyfikę tego procesu, a skład oleju gwarantować jego prawidłowy przebieg i odpowiednią jakość powierzchni walcowanej.

Wstępne badania laboratoryjne nad doborem emulgatorów potwierdziły możliwość uzyskania stabilnych emulsji, składających się z oleju mineralnego SAE 30/95 i kompozycji niejonowych surfaktantów typu: alkoksylowane nony- lofenole i alkoksylowane alkohole, zastosowanych łącznie w ilości 7,5\% $(\mathrm{m} / \mathrm{m})$.

Badania porównawcze w aparacie czterokulowym wpływu dodatków EP (siarkowego i fosforowego) na właściwości smarne olejów wykazały korzystne działanie dodatku siarkowego oraz brak działania dodatku fosforowego. Poziom dozowania dodatku siarkowego wynosił $5 \%(\mathrm{~m} / \mathrm{m})$, a fosforowego $-2,5 \%(\mathrm{~m} / \mathrm{m})$. Z badania cząstek fazy rozproszonej metodą DLS wynika duża niejednorodność analizowanych próbek emulsji, co świadczy o rozbiciu dodatków stosowanych w oleju na mniejsze krople o średnicach od 134 do $205 \mathrm{~nm}$, a oleju mineralnego na większe krople o średnicach od 1191 do $1666 \mathrm{~nm}$.

Prosimy cytować jako: Nafta-Gaz 2017, nr 2, s. 126-132, DOI: 10.18668/NG.2017.02.08

Artykuł nadesłano do Redakcji 30.11.2016 r. Zatwierdzono do druku 20.01.2017 r.

Artykuł opracowano na podstawie pracy statutowej pt.: Właściwości ochronne cieczy do obróbki plastycznej na zimno blach stalowych - praca INiG - PIB na zlecenie MNiSW; nr zlecenia: 0099/TO/16, nr archiwalny: DK-4100-90/16.

\section{Literatura}

[1] Dobrucki W.: Zarys obróbki plastycznej metali. Wydawnictwo Śląsk, Katowice 1975.

[2] Erbel S., Kuczyński K., Marciniak Z.: Obróbka plastyczna. Wydawnictwo PWN, Warszawa 1986.

[3] Gierzyńska M.: Tarcie, zużycie i smarowanie w obróbce plastycznej metali. Wydawnictwa Naukowo-Techniczne, Warszawa 1983.

[4] Głownia J.: Nowe tendencje w produkcji odlewanych walców hutniczych. Hutnik - Wiadomości Hutnicze 1998, nr 1, s. 24-29.

[5] Łędzki A., Zieliński K., Klimczyk A.: Podstawy technologii wytwarzania i przetwarzania. Akademia GórniczoHutnicza, Kraków; http://home.agh.edu.pl/ zmsz/pl/pliki/ ptwip/06_Przerobka_plastyczna.pdf (dostęp: 20.06.2016).

[6] Łuksza J.: Elementy ciagarstwa. Wydawnictwo Akademii Górniczo-Hutniczej, Kraków 2001.

[7] Materska M., Wojtasik M.: Zastosowanie Transmisyjnej Mikroskopii Elektronowej oraz techniki Dynamicznego Rozpraszania Światła $w$ badaniach koloidalnych dodatków uszlachetniających do paliw zawierajacych tlenki żelaza. Nafta-Gaz 2010, nr 8, s. 733-739.

[8] Moller U.J., Boor U.: Lubricants in operation. Mechanical Engineering Publications Limited, Londyn 1986.

[9] O'Brien R.D.: Fats and Oils. Formulating and Processing for Applications REC PRESS, New York 2004.

[10] Okoniewski S.: Technologia maszyn. Wydawnictwa Szkolne i Pedagogiczne, Warszawa 1995.

[11] Olszewski M., Romanowski M., Magda J.: Technologia walcowania, walcarki, narzędzia i urzadzenia specjalne do walcowania. Obróbka Plastyczna Metali 2008, tom XIX, nr 3.

[12] Pacyna J., Krawczyk J.: Wptyw obróbki cieplnej na strukture $i$ wtasności staliw stosowanych na walce hutnicze. Hutnik - Wiadomości Hutnicze 2004, nr 7-8, s. 370-374.

[13] Podniało A.: Paliwa oleje i smary w ekologicznej eksploatacji. Wydawnictwa Naukowo-Techniczne, Warszawa 2002.

[14] Skoblik R.: Technologia metali II. Smary w obróbce plastycznej; www.pg.gda.pl/ rskoblik/tm/pliki/...II.../Technologia_metali\%20_II_smary.pptx (dostęp: 6.06.2016). 
[15] Spuzic S., Strafford K.N., Subramanian C., Savage G.: Wear of hot rolling mill rolls: an overview. Journal Wear 1994, vol. 176, s. 261-271.

[16] Stepina V., Vesely V.: Lubricants and special fluids. Elsevier, Amsterdam 1992.

[17] Wesołowski Z.: Podstawy walcowania. WGH, Katowice 1960.

[18] Zajezierska A.: Smarowanie tożysk tocznych. Nafta-Gaz 2009, nr 12, s. 982-992.

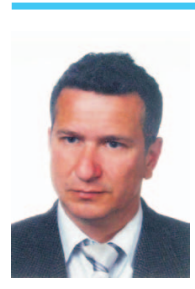

Mgr inż. Artur ANTOSZ

Starszy specjalista badawczo-techniczny w Zakładzie Olejów, Srodków Smarowych i Asfaltów.

Instytut Nafty i Gazu - Państwowy Instytut Badawczy

ul. Lubicz 25 A

31-503 Kraków

E-mail: artur.antosz@inig.pl

\section{Patenty}

[19] Opis patentowy US 5555756 A. Zgłoszenie US 08/377.453 z 24.01.1995. Udzielony 17.09.1996. Method of lubricating steel strip for cold rolling, particularly temper rolling.

[20] Opis patentowy WO 2010129953 A1. Zgłoszenie PCT/ US2010/034232 z 10.05.2010. Aqueous solution lubricant for steel cold rolling.

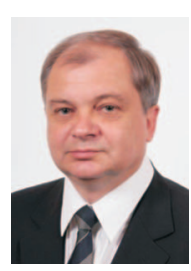

Mgr inż. Stefan PTAK

Główny specjalista inżynieryjno-techniczny; kierownik Zakładu Olejów, Srodków Smarowych i Asfaltów

Instytut Nafty i Gazu - Państwowy Instytut Badawczy ul. Lubicz 25 A, 31-503 Kraków

E-mail: stefan.ptak@inig.pl

\section{SRODKI SMAROWE 2017}

KRYNICA ZDRÓJ, 10-12 MAJA 2017 R.

\section{ZAPRASZAMY}

- producentów środków smarowych, olejów bazowych, dodatków do olejów, smarów i cieczy technologicznych

- dystrybutorów komponentów do środków smarowych

- pracowników działów B+R

- kadrę zarządzającą gospodarką smarową

- $\quad$ przedstawicieli uczelni i instytutów badawczych

- $\quad$ producentów i dostawców sprzętu laboratoryjnego

- użytkowników środków smarowych

\section{WWW.SRODKISMAROWE2017.INIG.PL}

\section{Organizatorzy \\ INSTYTUT NAFTY I GAZU \\ CEC POLSKA \\ Stowarzyszenie Wspotpracy Przemys
Naftowego i i Samochodowego}

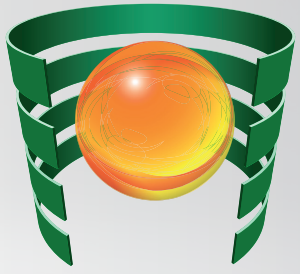

\section{REJESTRACJA UCZESTNIKÓW}

Joanna Oleksik

Tel. 126177495

e-mail: srodkismarowe@inig.pl 